\title{
Study on prevention implementation in tunnels construction: Marão Tunnel's (Portugal) singularities
}

\section{Estudio sobre la implementación de la prevención de riesgos laborales en la fase de construcción de túneles: caso particular del Túnel de Marao II (Portugal)}

Manuel L. Tender (Main and Corresponding Author)

University of Minho, Civil Engineering Department, Azurém Campus

4800-058 - Guimarães (Portugal)

manuel.tender@xispoli.eu

Francisco F. Martins

Institute for Sustainability and Innovation in Structural Engineering (ISISE)

University of Minho, Civil Engineering Department, Azurém Campus

4800-058 - Guimarães (Portugal)

ffm@civil.uminho.pt

\section{João P. Couto}

Centre for Territory, Environment and Construction(C-TAC)

University of Minho, Civil Engineering Department, Azurém Campus

4800-058 - Guimarães (Portugal)

jpc@civil.uminho.pt

Alfonso Cortés Pérez

AC2 Systems Consultancy

C/ San Marino, 3, Bajo A - 28022 - Madrid (Spain)

alfonso.cortes@ac2sc.es

Manuscript Code: 687

Date of Acceptance/Reception: 17.03.2017/12.09.2015

DOI: $10.7764 /$ RDLC.16.2.262

\begin{abstract}
The investment in tunneling shows an worldwide expansion trend. Reduction of risks, as part of the financial strategy of the stakeholders, has been the focus of several research studies. This paper aims to describe the construction risk prevention, in terms of occupational accidents and diseases, of the 2nd phase of the Marão Tunnel (Portugal) - the longest roadway tunnel in the lberian Peninsula excavated with Sequential Method -with the particularity of the works being interrupted, leaving the tunnel only with primary lining for three years. The methodology is based in: 1) identification, by literature review, of most typical preventive measures and assessement of their applicability in the case study; 2 ) description of new preventive approaches. The paper will start with a history of work accidents, followed by the case study and, finally, it will delve into the preventive measures applied, as well as the new approaches, such as over-runs, falling blocks and risks associated with the suspension of works. Measures identified in literature were implemented and their validity was assessed. New approaches provided an safer and quickest way to work. This study is relevant to future tunnelling sites, since it is a good example of risk management using new approaches.
\end{abstract}

Key words: New Austrian Tunneling Method (NATM), Sequential Excavation Method (SEM), risks, safety, tunneling.

Resumen

La inversión en construcción de túneles muestra una tendencia de expansión mundial. La reducción de los riesgos laborales, como parte de la estrategia financiera de las empresas, ha protagonizado varios estudios científicos. Este artículo describe la seguridad laboral implementada durante la construcción de la 2a fase del Túnel de Marão (Portugal), el túnel carretero más largo de la Península Ibérica ejecutado mediante el Método de Excavación Secuencial, con la particularidad de que su ejecución fue interrumpida durante tres años manteniendo el túnel sólo el revestimiento primario. La metodología se basa en: 1) identificación, mediante revisión bibliográfica, de las medidas preventivas más habituales y evaluación de su aplicabilidad al caso de estudio; 2) descripción de nuevos enfoques preventivos. El artículo comienza analizando un histórico de accidentes, seguido por el estudio de caso y finaliza profundizando en las medidas implementadas y en los nuevos enfoques, como sobrecargas, caída de bloques y riesgos asociados a la suspensión de las obras. Se implementaron medidas identificadas en la bibliografía y se evaluó su validez. Los nuevos enfoques proporcionaron una manera más segura y rápida de trabajar. Este estudio es relevante para el futuro de la construcción de túneles por la aplicación de nuevos enfoques. 
Underground works have been carried out for several thousands of years and for several reasons, including housing, water supply or shelter. Throughout the centuries, underground works have evolved and they have received a major boost between 1830 and 1850, with the rise of the infrastructures (Kovári, 2003).

At the time, several tunnels had to be built in order to overcome topography obstacles, since the tracks could not have pronounced bends or steep slopes and seeing that it would have been more expensive to build longer tracks to avoid the mountains rather than going through them. Nowadays, there are several underground works under construction in several countries: for roads and railways, hydraulic and hydroelectric power plants, and for waste storage. At the international level, the amount of underground works will certainly rise in the future, due to the fact that there will be space and environmental issues constraining surface works. Probably, the majority of future tunnels will be excavated using tunneling boring machines, but the SEM will remain the first choice in challenging soils with altered conditions (Jodl \& Resch, 2011).

This study stresses the importance of studying and researching the implementation processes of occupational risk and safety measures in tunneling.

\section{Accident prevention in tunnels}

The list of risks in tunneling is as extensive as the list of risks in surface works, or even more. Quite often, the level of risk is higher in underground works for the following reasons: a high degree of uncertainty concerning the nature and changing characteristics of the rock mass and the fact that these are works in a confined space (Lamont, 2002).

For several years, tunneling has been prone to accidents with multiple victims. For example, in the railway tunnel of S. Gotthard (1872-1882), 177 workers lost their lives (Gánez et al., 2011). Table 1 shows some figures of fatal accidents in tunneling (Gascon et al., 2008).

Table 1. Fatal accidents/Kilometer (Source: personal compilation).

\begin{tabular}{llcc}
\hline Name & Dates & Length $(\mathrm{km})$ & Fatal accidents/km \\
\hline St Gotthard & $1872-1882$ & 15 & 11.8 \\
Mt Blanc & $1956-1962$ & 12 & 1.4 \\
Seikan & $1970-1987$ & 90 & 0.4 \\
Argentera & $1882-1990$ & 4 & 3.5 \\
Channel Tunnel & $1988-1995$ & 160 & 0.056 \\
Crossrail & $2012-2017$ & 42 & 0.024 \\
\hline
\end{tabular}

Of course, accidents in tunneling can be originated by structural issues or can stem from causes more connected to safety at work issues. This paper aims to analyze the latter.

There are currently no compilations of statistics for occupational accidents and diseases in tunneling, which creates a gap in knowledge.

However, according to the literature review by the lead author the following conclusions can be reached concerning the SEM (Tender, 2014):

- The main causes of work accidents are connected to transport/movement of workers (Vogel \& Kunz-Vondracek, 2013), and falling blocks (Longo, 2006);

- $\quad$ The great majority of occupational diseases can be linked to contact with chemicals (Jodl \& Resch, 2011).

This study is part of a wider one analyzing good tunneling health and safety practices. At this stage, with the chosen methodology, it aims to present the good practices found in the selected case study, using SEM. 
The methodology used for this research started with a literature review and survey of the state-of-the-art, to find out which work accidents and occupational diseases are more common in this kind of works and what are the coping measures traditionally implemented. Afterwards, the study focused on the Marão Tunnel II, to assess the applicability of the preventive measures found in the literature to this case study and to see what new measures were implemented to reduce risks.

This work was chosen because it will be the longest tunnel in the Iberian Peninsula and also due to the fact that it is becoming famous for the adoption of safety best practices. The evolution of the works was followed by the lead author, as Health and Safety Construction Coordinator, being able to collect the results obtained. The good practices found were then analyzed and those that represent new approaches to known issues were selected. This is deemed to differentiate this study from previous ones and also to allow for future use of the information in coming tunneling works.

\section{Presentation of case study}

\section{Characterization of case study}

The Marão Tunnel is located in the North of Portugal and it will allow the underground crossing of the Marão Mountain, along the West-East axis, between Ansiães-Amarante and Campeã-Vila Real.

The Tunnel consists of two parallel galleries, with $5667 \mathrm{~m}$ in length. There will be 13 connections between the tunnels, 6 of which will be exclusively for pedestrians, 6 for vehicles and pedestrians, and 1 for pedestrians and electrical facilities. Figure 1 shows the standard section. The route profile in the tunnels shows an almost continuous upward longitudinal slope of $2.5 \%$. The budget for the works is $€ 88099873.47$.

The construction of the tunnel was awarded by "Portugal Infrastructures" to "Teixeira Duarte/EPOS Joint Venture"; "EPOS" is responsible for the excavation, primary support and final lining.

Figure 1. Standard section in Marão Tunnel (Source:personal compilation).



\section{Time framework}

The excavation works (1st phase) started in July 2009 but were suspended, due to financial constraints, in July 2011, with $3961 \mathrm{~m}$ left to be excavated. The works were expected to be eventually resumed in 2014, but in the meanwhile only those works designed to monitor what had already been constructed were carried out.

This time gap could have led to weaknesses in the primary lining, thus increasing the risk of blocks falling over workers and equipment (Tender et al., 2015b). So, for the preparation of tenders for the second phase of construction (2014), the tunnels were inspected to assess their overall condition. This inspection showed that the rock mass was globally stable and no alarming convergence situations were identified. Most of the pathologies identified were related to slabbing, falling blocks and cracking of shotcrete. These pathologies were not related to rock mass movements nor to the durability of the primary support applied. They were located in places of the mass with unfavourable geologic and geotechnical features (i.e, unfavourable diaclases which, due to the decompression of the mass, tend to load the support, or else concentration of water flows) which were worsened by the natural deterioration over time of the primary support and the poor bond between the shotcrete and the rock mass. This conclusion was supported by the fact that there were no slabbing or falling blocks due to breakage of Swellex anchors, which, according to the technical documentation, have a service life of 3 years. Therefore, it can be concluded that the anchors were able to stabilize 
blocks that were unstable due to the partitioning of the rock mass and also that the blocks that did fall were in places with unfavourable partitioning of the mass that had not been identified during the excavation phase and, thus, had not been suitably anchored or supported.

In October 2014, the second phase of excavation and the final lining works were resumed (waterproofing and drainage of water from the mass, installation of reinforcement and concreting of the final lining).

\section{Construction process}

\section{Reinforcement of areas already built}

Integrating prevention in the design phase allows to minimize risks at their root and gives time to identify and treat any deviations before the risks become unbearable (Eskesen et al., 2004). It also allows for fundamental changes to be made when needed. Collapses or excessive deformation of the tunnel's primary support are one of the main causes of accidents in tunnels (Longo, 2006). They can occur due to natural phenomena with long term effects, like water infiltrations, effects of temperature and erosion. In Marão Tunnel II, this risk was managed since the design phase, as interrupting the works in 2011 could have led to situations where structural safety might interfere with occupational safety. In order to reduce the risk of further degrading of primary support, the first task in the beginning of the second phase of works was to reinforce the areas excavated in the first phase. Before resuming the work, the contractor conducted a pathology survey (results in Table 2).

Table 2. Type of pathologies found in the beginning of excavation (Source: Self elaboration).

\begin{tabular}{lcccc}
\hline & Amount (Un) & Total (\%) & Crown arch (\%) & Sidewalls (\%) \\
\hline Slabbing & 128 & 55.0 & 41.4 & 58.6 \\
Concrete cracking & 72 & 31.0 & 36.1 & 63.9 \\
Loose blocks or falling blocks & 22 & 9.0 & 27.3 & 72.7 \\
Convergence values above & & & & \\
recommended & 10 & 4.0 & 40.0 & 60.0
\end{tabular}

Slabbing was the main pathology found and it must be stressed the fact that it increases the risks in the pedestrian and vehicle circulation areas manifold.

In order to rank the pathologies in terms of seriousness, three levels of structural preventive actions were defined by the contractor. Table 3 shows the quantification of those levels, according to the data collected on site.

Table 3. Percentage distribution of implemented measures (Source: Self elaboration).

\begin{tabular}{lcccc}
\hline & Amount (Un) & Total (\%) & Crown Arch (\%) & Side Walls (\%) \\
\hline Type 1 & 119 & 47.2 & 35.3 & 64.7 \\
Type 2 & 117 & 46.4 & 43.6 & 56.4 \\
Type 2 with anchors when needed & 6 & 2.4 & 16.7 & 83.3 \\
Type 2 with no traffic allowed & 4 & 1.6 & 0.0 & 100.0 \\
Type 2 with convergences section & 3 & 1.2 & 0.0 & 100.0 \\
Type 3 with convergences section & 0 & 0.0 & 0.0 & 0.0 \\
\hline
\end{tabular}

They are as follows:

Type 1: Keep under surveillance;

Type 2: Local scaling of the rock mass in risk of falling and of primary support, with re-application of shotcrete; possible application of anchors or stopping workers and equipment from staying in the area; possible installation of convergences section; 
Type 3: Reshaping of excavation section and application of a sturdier primary support, with additional instrumentation; possible installation of convergence sections.

Despite this initial effort, it is important to keep in mind that the risk of slabbing and cracking would remain during construction works. This requires the setting up of additional preventive occupational measures, which will be detailed later in the paper.

\section{Excavation and primary lining}

The method used is the Sequential Excavation Method (SEM), traditionally named New Austrian Tunneling Method (NATM). This method consists in applying a thin layer of sprayed concrete on the support of the excavation as quickly as possible, to create an auxiliary arc, and the deformation of the ground is a function of time until equilibrium is reached.

The method has the following phases, shown in Figure 2 (Tender et al., 2015a).



They are as follows:

1: Topographic marking of the excavation face;

2, 3 and 4: Sequential excavation of the rock mass, by mechanical means or with explosives;

5: Ventilation of the excavated area, to clear the contaminated air from the atmosphere after the excavation (namely when it was done with explosives) and ensure its replacement with fresh air with the minimum standards of breathability;

6: Removal of excavation products to landfill, to allow space for the scaling and concrete spraying operations to begin; 7: Scaling of the excavation site, by mechanical and manual means, to remove unstable blocks of pieces of rock mass and ensure that the mass has the necessary integrity conditions for applying the first layer of sprayed concrete;

8: Application of a sprayed concrete layer and stabilizing devices: sprayed concrete, with possible addition of metallic fibres, metal crankshafts, anchors and forepoling, improving the resistance of the rock mass.

The Method promotes the deformation of the mass adjacent to the excavated section (which then functions as bearing element). This deformation, minimized by the application of the first concrete lining (and stabilizing devices), allows for the redistribution and reduction of maximum tensions, preventing the rock mass from going into an unstable situation, thus promoting, through primary support, the maximum resistant capacity of the site. It is a highly observational method (Lamont, 2002), and monitoring rests on a system of instruments (inclinometers, strain gauges, piezometers and convergences) embedded in the lining, in the rock mass and in boreholes, which dictates the need for reinforcement or the possibility of easing the provisional support.

\section{Results and discussion}

It will now be presented the results obtained and discussed their relevance. The results shown, in order to be better understood, will be divided in six big groups: workforce management, managing emergency situations and accidents, accesses and pedestrian / machinery movements, managing blasting operations, risk of falling fresh sprayed concrete, specificities. 


\section{Workforce management}

\section{Training}

$84 \%$ of risks are noticed depending on the worker's experience, training and knowledge (Garzón et al., 2013). Therefore, training is a very important aspect, because it focuses on the individual attitudes of the workers, an important factor for managing teams (Lamont, 2006). The International Tunneling Association acknowledged its importance, and published an illustrated manual called "Safety in Tunneling", which was translated to several languages. The fact that SEM involves a large number of workers increases the vulnerability to human error (Health and Safety Executive, 1996). In turn, this increases the importance of "training" as a way to reduce the probability of adoption of dangerous individual attitudes. At this point, it shall be addressed two kinds of training: induction, or basic, training and specialization training.

When it comes to basic safety training, several countries adopted systems to ensure a minimum level of training (e.g., in Spain, the "Tarjeta Profissional de Construcción"). In some of these countries it is mandatory to attend this training (and pass the relevant exam giving access to the relevant card) in order to be able to go into working sites. In Portugal there is no definition of the minimum training level the employee must have. Usually, workers receive a very short-term safety and health training (often of less than an hour), telling them the basic safety rules they must follow (Tender et al., 2015b). In the Marão Tunnel II, in order to overcome this problem, a custom-made system was set in place: an 8 hour-long basic training to all workers (a total of 408 training hours).

As for the specialization training, considered as essential training (British Standard Institute, 2011), several models have been adopted. It is worth mentioning the Spanish case: all workers must undergo a specific 20 hours training on the work they will be performing. In Marão Tunnel II, an additional 8 hours specific training was adopted for those workers dealing with excavation and primary support operations (a total of 165 hours).

There was also a system of tutoring for the heavy machinery drivers. Training was divided into two parts. First, there is an induction training conducted by the internal trainer of "EPOS" to 56 drivers, consisting of: skills assessment on equipment operation (if the worker does not reach a set performance level, he will not be allowed to operate the equipment until he receives further training and is reassessed); practical training in working environment (the training is personalized and its length will depend on the worker's proficiency level and difficulties, with the goal of improving his technical skills in operation, maintenance and safety of heavy machinery). It should be noted that the option of using an internal monitor (imbued with the culture of the company, with high knowledge of each machine, fitting the necessary schedules and well-respected, due to his wide experience and time of service at the company) has proved extremely useful in the processes of recruitment and selection as well as the training and evaluation processes of technical skills of operators.

The second part is a further training which will last from 2 to 5 days, and is conducted in partnership with equipment suppliers to 64 drivers. This training had the aim of providing knowledge to reduce productivity losses through the correct use of mobile production equipment, namely at the level of risk of accidents prevention and 1st level maintenance.

The system was implemented from the beginning of works, and there have been steady improvements in worker's and drivers behaviours with no occurrence of serious accidents.

Some additional specific training was conducted on topics such as road safety (since there is often ice on the road) and Communication of Near-misses.

\section{Systems of incentives and penalties to workers}

Motivation is strengthened when the teams are acknowledge and rewarded for their success(Telo, 2014). One of the ways of achieving this is setting up a system of incentives(for encouraging and rewarding safe behaviour) or penalties (in case of non-compliance with safety rules)(Hasan \& Jha, 2013). The use of incentives and penalties resulted in better safety performance and in fewer accidents, compared with projects without this dual model.

It must be stressed that the distribution of incentives must be balanced with penalties imposed on the worker in the event of non-compliance with prevention rules. The company in charge of the underground works in Marão Tunnel, EPOS, is a good example, since they have adopted this system of incentives and penalties (Tender et al., 2015b). In terms of incentives, the system provides for payment of monthly performance premiums, depending on the performance reached. As for penalties, they depend on the seriousness of the situation and are indexed to productivity and safety 
bonuses, which mean that each type of occurrence has an associated economic penalty. This system has resulted in a significant reduction of unsafe acts and of repeated unsafe acts; an improved operational control; a natural selection of employees that deserve to stay in the company; and a greater transparency in the performance evaluation of employees.

This system was implemented and monitored periodically so that there was no risk of accidents or near-misses not being reported in order to avoid losing the reward. In addition, an awareness raising campaign for near-misses reporting was carried out.

\section{Managing emergency situations and accidents}

\section{Emergency planning}

Tunneling works are prone to several types of emergency situations, particularly burying, electrification/electrocution, being hit by a vehicle, road accidents, intoxication or lack of oxygen. Besides these higher probability situations, several other scenarios should be considered, despite their low probability of happening: explosion, caving-in, fire and flooding, sudden air contamination and power failure in the ventilation system.

The first step to minimizing damages from emergencies is to set up a contingency plan for each scenario, covering first aid, rescue and evacuation operations, and the maintenance of the minimum power supply for operation of vital infrastructures, which should be done in cooperation with external support bodies (British Standard Institute, 2011).

For the evacuation of the injured in work sites where road access is difficult, having a heliport is a good way to reduce the time taken to take the person from the portal to the nearest hospital(Arup, 2012). In the Marão Tunnel II the decision to have a heliport was taken, following meetings with the National Authority of Civil Protection where the possibility of a timely arrival of emergency services to the site was assessed. From these meetings also came the need to set aside some space to install a field hospital in case of need.

Additionally, there was a drill carried out together with the Vila Real Volunteer Firefighters in order to assess the suitability of the procedures for the rescue of workers from the tunnel.

\section{Managing accidents and near-misses}

Everybody acknowledges that all accidents must be reported to the employer. In a study on the causes of non-reporting of accidents to the employer $27 \%$ of workers stated that they had failed to report an accident at least once (Moore et al., 2013). The main reason for not reporting an accident is the small dimension of injuries (72\%). Therefore, one of the great challenges facing current companies is overcoming this personal choice of their workers and helping them to report all accidents, even minor ones. One of the ways to achieve this may be adopting a constructive rather than punitive approach and explicitly encouraging workers to talk about their concerns. In the Marão Tunnel, there were meetings raising the awareness for the need to report accidents, which improved the identification of situations which would have been difficult to analyze otherwise.

It is important to study the so-called near-misses, since those events traditionally precede accidents (Ceyhan, 2012) and are, therefore, an extremely useful source of information for the study of events. Thus, reporting and analyzing nearmisses is fundamental to avoid new events and effectively reduce the amount of accidents. The goal is to get a proactive response, which happens when a corrective measure is implemented immediately after the occurrence of a near-miss (Kecojevic \& Radomsky, 2005). In Marão Tunnel II, the need to have information on near-misses was stressed. This choice revealed fruitful and led to a reinforcement of training and a revision of procedures.

\section{Accesses and pedestrian / machinery movements}

\section{Site access roads}

Marão Mountain is characterized by lands with deep valleys of high slopes. Excavation works requires a great movement of earth loading and moving machinery, namely to carry debris from the excavation face to the landfill (which is far away from portals). The machinery has to ride on the slope of the hillside, with a high risk of rolling and tipping over of machinery to lower levels (slopes with a height exceeding $40 \mathrm{~m}$ ). Incidentally, in the 1st phase of construction of the Tunnel there was a serious accident due to the careless approach to the slope and subsequent tipping and rolling over 
of the vehicle to the base of the valley. In Marão Tunnel II, the use of a land cord with tapped material from excavation, defended by Gascon (2008), was implemented, to delimit the slope border (so as to minimize the likelihood of approaching the gap), with very positive effects. This was complemented by the use of portable concrete barriers in the most dangerous stretch (Figure 3).

Figure 3. Demarcation of slope border (Source: Lead author).



\section{Traffic inside the tunnel}

Most accidents in tunneling are related to traffic and transportation(Vogel \& Kunz-Vondracek, 2013). Indeed, there is low visibility in the small confined space of the tunnel, and there is a high risk of collision between workers and machinery. Of course, when these accidents happen, the machinery is unharmed but the worker will be injured. Since SEM requires extensive use of heavy machinery for loading and removing the debris to the landfill (loader shovel, front shovel, dumpers, trucks or rails), the risk of run-overs increases. Blind spots are also worth mentioning, since they create areas of poor to no visibility between the machinery and the worker (Lamont, 2002). Adding to that, the machinery itself has a lot of inertia, which makes it difficult to change direction swiftly.

Installing rear video cameras, instead of rear view mirrors or signalers, is a suitable preventive measure for these risks (Vogel \& Kunz-Vondracek, 2013). The video camera system, in use in Marão Tunnel II for dumpers, consists of a camera installed in the rear of the machinery and a screen near the driver's seat (Figure 4). It was implemented in the transalpine tunnels following several run-over accidents and resulted in unequivocal improvements in terms of safety. This allows the driver to have better visibility, reducing the risk of run-overs (Tender et al., 2015b).

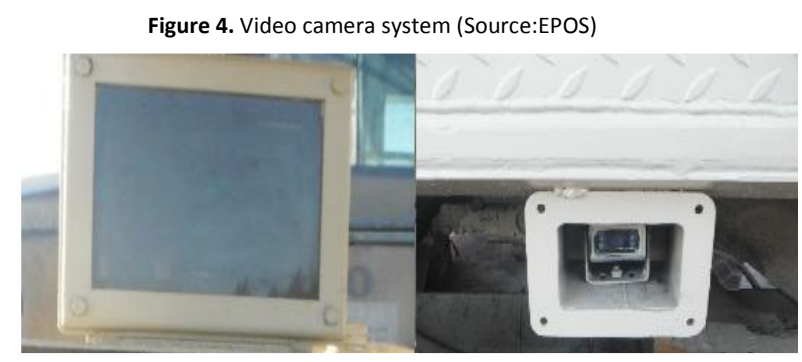

There was the possibility of dirt accumulating on the image collection and viewing systems, so special attention was paid to check that they were conform to the cleanliness requirements.

In Marão Tunnel II, this system improved the traffic flow of machinery, minimizing the risks of getting too close to the workers and even run-overs.

\section{Managing blasting operations}

The explosives industry has witnessed great strides in terms of material and equipment used, with the goal of improving yields, ensuring better stability conditions for transportation and handling of explosives, and lowering the amount of resulting toxic fumes. There is currently a trend to use emulsions as the explosive product for excavation, rather than "ANFO" (Stipek et al., 2012). Emulsions have several advantages, including having greater stability during transport and handling, a very low content of toxic contaminants, highly resistant to mechanical or thermal actions, inexpensive, highly resistant to water, and having high blasting speeds (Tender et al., 2014). In Marão Tunnel II, on the west side galleries, this was the choice in terms of explosives. To apply them, the technique used was pumping the emulsion 
directly into the holes (the most advanced technique to date), thus minimizing the risks linked to the transportation and handling of explosives (since it is only explosive after being pumped into the hole). This evolution gives this system one of the advantages that the ANFO system presents when compared to cartridge emulsions: higher reliability in loading, because there is a lower risk of the explosive cartridge getting stuck in the holes (which increases the danger of not blasting the explosive due to lack of contact with adjacent cartridges). This bulk application has also allowed decreasing the risk of workers being exposed to falling blocks from the excavation face during explosives assembly. In the present digital era, the explosives industry is slowing moving towards high-tech initiation systems - electronic detonators. Even though things are evolving slowly due to the high cost of this system, a lot of users have been proving that the safety and productivity gains completely justify the investment (Kara et al., 2014). In Marão Tunnel II, electronic detonators and non- electric detonators were used for initiation. Electronic detonators have many advantages starting with the protection offered by the electronic system, since the flaming of the filament crossed by the electric current only occurs when a chip in the detonator gives the information that the piece, which has a unique code (so, with no possibility of error associated with a delay element, as the one in the electrical detonators), may fire. Besides, it is insensitive to parasitic or erratic currents, there are no limits to the number of delays per blast, it has better delay periods (maximizing the use of available energy, producing a better fragmentation), there is a reduction in vibrations and a higher reliability of detonation, resulting in higher productivity.

\section{Risk of falling fresh sprayed concrete}

Applying a layer of sprayed concrete as initial support is one of the characteristics of the SEM. After the spraying of concrete for primary lining, and before the shotcrete gains sufficient strength, there is a risk of fresh concrete fractions falling from the crown arch or the side walls (Tender et al., 2015b). For this reason, getting a suitable resistance in a timely manner is a key element which, besides affecting productivity, also affects safety. To deal with this problem, it is recommended to create exclusion zones, preventing access to risk areas during and immediately after the spraying of concrete (Crossrail, 2013).

In Marão Tunnel II, this was considered an unbearable risk. Therefore, the preventive measure taken was to create exclusion zones based on the average time needed for the concrete to set. These zones correspond to the area surrounding the spraying concrete equipment operator (to the excavation front), where there is a risk of fractions of fresh concrete falling. This measure made it possible, even in cases with greater influx of water and where the sprayed concrete application was harder, to protect the worker at all times.

\section{Specificities}

\section{Rock mass excavated 3 years ago}

Collapses or excessive deformation of the tunnel's primary lining are one of the main causes of accidents in tunnels(Longo, 2006). They can occur due to natural phenomena with long term effects, like water infiltrations, effects of temperature and erosion. One of the ways to reduce the number of work accidents is to act in the design phase, since a high percentage of accidents that occur is connected to decisions taken during this stage (which does not mean that it is an exclusive cause) (Arévalo, 2013). Therefore, and given that in the Marão Tunnel II issues related to structural safety, that had to be dealt with in the design phase, interfered directly and permanently with issues of occupational safety (because the suspension of work in 2011 caused additional risks to the usual risk of fragments of primary lining falling), an approach of prevention in the design phase was required. The approach to risk was initiated by the Safety and Health Design Coordination, with the decision to implement specific periodic monitoring reports, in order to detect problems in the rock mass or in the primary lining.

To minimize the risk of materials falling on workers and machinery in the transit areas, contractor established the following preventive measures that were adopted before the resumption of the works:

- $\quad$ Reinforcing the areas already built as soon as possible;

- $\quad$ Setting up of "risk areas" with circulation ban in type 2 areas, identified as unsafe;

- Observation of installed supports as part of the daily routine of those involved;

- Ban on pedestrian circulation in the galleries (the access to the excavation face was by vehicle), minimizing theirs exposure to the risk of falling blocks;

- Establishment of a strict instrumentation plan that is easy to interpret; 
- Promotion of regular joint surveys to the condition of the sprayed concrete and the rock mass, in the presence of designer representative, geology, representative of the work manager and Safety and Health Construction Coordination.

These measures ensured that, as the works evolved, new pathologies could be identified and dealt with in a timely manner, thus minimizing the risk to workers and machinery.

\section{Simultaneous work: excavation and primary support / final lining}

The construction of Marão Tunnel II has a close deadline, which forced the excavation to take place at the same time as the final lining. This option creates air quality constraints: if air is inflated in the excavation face, the entire length of the galleries (including the place where final lining operations are being carried out and the portal) is continuously crossed by a cloud of air which can contain various contaminants:

- Mineral dust originating from the excavation face. In rock masses with a high content of quartz, this is a situation worthy of all attention, due to the possible presence of respirable crystalline silica, which can be fatal (Chapman et al., 2010)

- Fumes created after blasting operations - air is blown in the excavation face, causing the exhaust of air contaminated with toxic gases through the galleries. Tunnellers who use "ANFO" explosives show a temporary reduction in lung function, whereas those who use emulsion do not(Furuseth et al., 2013). The most likely explanation for the changes observed is the peak exposure to nitrogen dioxide. However, pumped emulsions do have low emission of toxic fumes but can produce hazardous ammonia fumes in the presence of heat, humidity and sprayed concrete(Vogel \& Kunz-Vondracek, 2013).

One option to minimize air contamination in tunnels (which can also increase the usual problems with lighting in underground works(Velasco et al., 2010), is the installation of curtains. In Marão Tunnel II, in order to separate spaces and minimize risks to the workers in charge of the final coating, the first choice was to install these curtains to contain the contaminated air cloud (and direct it, through crossing galleries, to the parallel gallery). However, this system failed to achieve the desired effect, for two reasons: first, curtains were fragile and easily damaged by repeated opening and closing, and secondly, sometimes curtains were opened before the cloud of fumes from the fire blast crosses that section. To solve this problem, gates were installed, which had a warning indicating the need to keep the curtain closed, shown in Figure 5. All the air quality values measured after that (measures were taken daily) were below the Exposure Limit Values set.

Figure 5. Delimitation gate of final lining area (Source: Lead author).

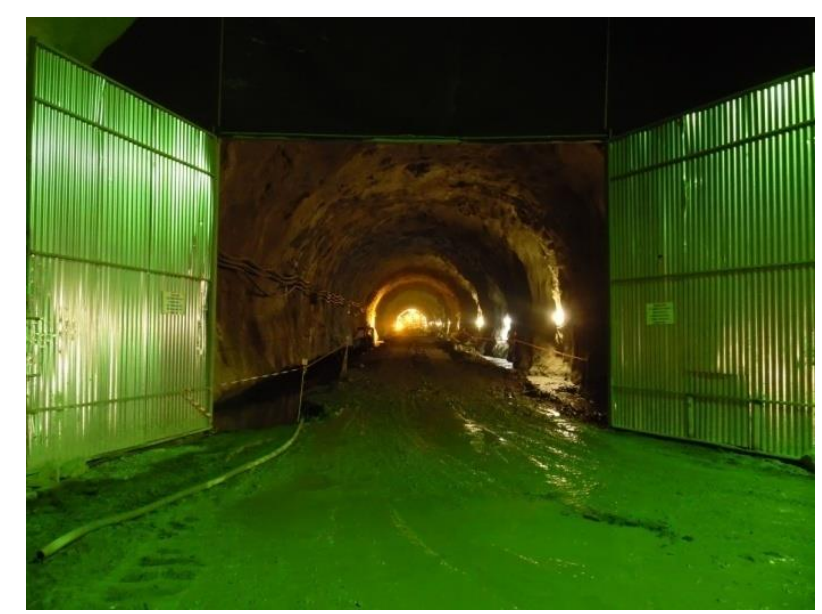

The results reinforce the need of addressing the risks identified in the literature. They also confirm the applicability, in this case study, of the preventive measures scientifically studied; they improve some of the solutions presented, and propose new approaches to risks.

The SEM is a method with many specificities and limitations that result in a set of risks for the construction phase. 
Given the existing constraints and those originated by the suspension of work for three years, it was found that the weaknesses of the mass / primary support required the adoption of two preventive approaches, in an integrated approach between structural safety and occupational safety and in a joint work between safety and health Coordinators, representative or designer, work management and geologists: reinforcement of areas already excavated (in terms of structural safety), and restriction of movement, accompanied by monitoring of the mass (in terms of occupational safety). These approaches allowed the proper monitoring of the mass and the detection of risky situations in a timely manner.

When it comes to machinery movement between portals and the landfill, the risk of tipping and rolling over has been decreased, making the event of an accident similar to the one that happened in the 1st phase of construction less likely. In terms of workers' attitudes, the number of hours of training and the system of incentives / penalties implemented allowed the workers to have a better understanding of the safety rules and have a proactive attitude to risk situations.

Regarding the risk of being run over, the combination of video systems in machinery with the tutorial training has allowed a better approach to risk by the operators.

The risk of inhaling hazardous fumes has been drastically reduced, allowing excavation sites and primary support operations ongoing with some proximity to final lining operations. The gradual use of explosives with less toxic fumes may eventually help to reduce this risk.

Approaching the risk of accidental explosion in terms of the products used and in terms of training, has allowed work to be carried out in a safe way. The use of technologically more advanced detonators should be included in the priorities of the project owners and contractors.

As for the risk of fresh concrete fragments falling, with the measure implemented the number of workers exposed to the risk decreased. This measure is not yet systematic at the international level, but this is a good opportunity to integrate it in the best practices for underground works.

Summing up, the measures identified in the scientific literature were implemented. New approaches were also implemented. It was found that new options adopted, although slightly changing the traditional construction procedures, provide an easier, safer and quickest way to work and constitute a significant advance in terms of scientific knowledge. Preventive measures applicability and validity in Marão Tunnel II was verified by:

- $\quad$ Last 226 days of construction without occurrence of occupational accidents with days lost;

- Zero occurrences due to detachment / displacement of blocks and sprayed concrete of 1st stage

- Zero suspensions of works by official entities;

- Absence of fatal work accidents during construction phase;

- Absence of records of occupational diseases during construction phase.

The fact that there is the need to implement some preventive measures that are identified in the literature but not included in the regulatory and legal framework, could promote the review and updating of the said framework.

The suitability of the new approaches is evidenced by their potential use in future works.

This paper will contribute to disseminate and support the implementation of preventive measures in new tunnels to be built with the SEM.

\section{Acknowledgements}

The authors would like to thank: "Infraestruturas de Portugal" and "Teixeira Duarte / EPOS Joint Venture" for their support; the participating partners in the R\&D Project associated to this paper: MOTA-ENGIL, ORICA, SIKA, DST; and Mrs. Alexandra Valle Fernandes for the review and translation of the paper.

This work was partly financed by FEDER funds through the Competitivity Factors Operational Programme - COMPETE and by national funds through FCT - Foundation for Science and Technology within the scope of the project POCI-010145-FEDER-007633. 
Arévalo, C. (2013). Integración de la prevención en el diseño de obras de construcción: relación con la siniestralidad laboral, análisis de su regulación normativa, bases conceptuales y desarrollo internacional. Informes de la Construcción, 65(531), 325-334. doi: doi: 10.3989/ic.12.006

ARUP. (2012). Southern Nevada Water Authority Contract 070F 01 C1 Lake Mead intake shafts and tunnel Project Specifications, USA.

British Standard Institute. British Standard 6164 - Code of practice for health and safety in tunnelling in the construction industry (2011).

Ceyhan, C. (2012). Occupational health and safety hazard identification, risk assessment, determining controls. (MsC in Civil Engineering), Middle East Technical University, Turkey.

Chapman, D., Metje, N., \& Stark, A. (2010). Introduction to Tunnel Construction. London: Spons Architecture Price Book.

Crossrail. (2013). Best practice guide SCL Exclusion zone management. London: Crossrail.

Eskesen, S. D., Tengborg, P., Kampmann, J., \& Veicherts, T. H. (2004). Guidelines for tunnelling risk management Tunnelling and Underground Space Technology, 19(3), 217-237. doi: 10.1016/j.tust.2004.01.001

Furuseth, K., Meraker, E., Hansen, T. V., Myran, T., \& Brustad, G. (2013). Recent studies of health effects in tunnel construction work in Norway. Report no13. Oslo: Norwegian Tunnelling Society.

Gánez, J., Guijarro, L., \& Ruiz, M. (2011, 10th May). Seguridad en la construccion de túneles. Paper presented at the International Rail Forum, Madrid.

Garzón, I., Martínez-Fiestas, M., \& Alonso, M. (2013). El riesgo percibido por el trabajador de la construcción: que rol juega ef oficio? Revista de la Construcción, 12(3).

Gascon, J., Laguna, M., Ruiz, M. R., \& Guijarro, L. (2008). Health and safety in tunnel construction Paper presented at the V H\&S Course in tunneling Madrid.

Hasan, A., \& Jha, K. (2013). Safety incentive and penalty provisions in Indian construction projects and their impact on safety performance. International Journal of Injury Control and Safety Promotion, 20, 3-12.

Health and Safety Executive. (1996). Safety of New Austrian Tunneling Method (NATM) Tunnels: HSE.

Jodl, H. G., \& Resch, D. (2011). NATM and TBM - comparison with regard to construction operation. Geomechanics and Tunnelling, $4,337-345$.

Kecojevic, V., \& Radomsky, M. (2005). Flyrock phenomena and area security in blasting-related accidents. Safety Sci. 43, 739-750.

Kovári, K. (2003). History of the sprayed concrete lining method-part II: milestones up to the 1960s. Tunnelling and Underground Space Technology $18,71-83$.

Lamont, D. (2002). Keynote Lecture - Overview of health and Safety in Tunnel Construction. Paper presented at the World Tunneling Congress, Sidney.

Lamont, D. (2006, 22th April). Occupational Health and Safety Risk Management in Tunnel Works - Keynote Lecture and Open Session. Paper presented at the World Tunnel Congress, Seoul.

Longo, S. (2006). Analysis and management of geotechnical risk in tunnels. (PhD Thesis in Mining Engineering), Instituto Superior Técnico, Lisboa.

Moore, J., Cigularov, K., Sampson, J., Rosecrance, J., \& Chen, P. (2013). Construction Workers' Reasons for Not Reporting Work-Related Injuries: An Exploratory Study. International Journal of Occupational Safety and Ergonomics, 19(1), 97-105.

Stipek, W., Galler, R., \& Bauer, M. (2012). 50 years of NATM-experience reports. Austria: ITA.

Telo, E. (2014, 6th March). Health and safety leadership as an sucess factor. Paper presented at the 11th International Congress in Safety and Health at Work, Porto.

Tender, M. (2014). Guide for work accidents and health diseases prevention in tunneling with NATM (Msc Thesis in Civil Engineering), Faculty of Engineering of University of Porto, Porto.

Tender, M., Couto, J., \& Ferreira, T. (2015a). Prevention in underground construction with Sequential Excavation Method. In Arezes et al. (Ed.), Occupation Safety and Hygiene III (pp. 421-424). London: Taylor \& Francis.

Tender, M., Couto, J., \& Gomes, A. (2015b). Portuguese strengths and fragilities on Safety and Health practices. In D. Kolic (Ed.), Promoting Tunneling in SEE Region (Davorin Kolic ed.). Dubrovnik: Hubitg.

Velasco, J., Herrero, T., \& Prieto, J. (2010). Metodología de diseño, observación y cálculo de redes geodésicas exteriores para túneles de gran longitud. Informes de la Construcción, 66(533), 1-10. doi: http://dx.doi.org/10.3989/ic.13.007

Vogel, M., \& Kunz-Vondracek, I. (2013,31th May). Safety and health in long deep tunneling-lessons learned in Swiss transalpine tunnel projects. Paper presented at the World Tunnel Congress, Genebra. 